NISTIR 7858

\title{
A Review of Test Artifacts for Additive Manufacturing
}

Shawn Moylan

April Cooke

Kevin Jurrens

John Slotwinski

M. Alkan Donmez

http://dx.doi.org/10.6028/NIST.IR.7858

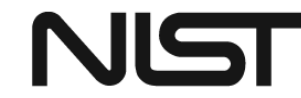

National Institute of Standards and Technology U.S. Department of Commerce 
NISTIR 7858

\title{
A Review of Test Artifacts for Additive Manufacturing
}

\author{
Shawn Moylan \\ April Cooke \\ Kevin Jurrens \\ John Slotwinski \\ M. Alkan Donmez \\ National Institute of Standards and Technology \\ Engineering Laboratory \\ Gaithersburg, MD 20899
}

http://dx.doi.org/10.6028/NIST.IR.7858

May 2012

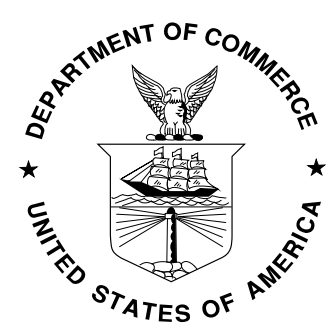

U.S. Department of Commerce John E. Bryson, Secretary

National Institute of Standards and Technology Patrick D. Gallagher, Under Secretary of Commerce for Standards and Technology and Director 
Abstract

A standardized test part can be used to quantitatively evaluate the performance of a machine or process. This document reviews existing test artifacts used to characterize additive manufacturing processes that are reported in the literature. Several aspects of the test artifacts and their use for performance characterization are discussed, including the purposes of the studies, important features found in various test pieces, and characteristics that are desirable in test pieces. The works were divided into four categories: test artifacts for comparing processes for decision making, test artifacts for evaluating individual processes, test artifacts for evaluating metal-based processes, and test artifacts for other uses. Many of the test parts have similar characteristics because research typically builds upon the findings of previous research, and many researchers may have been influenced by "rules" put forth in earlier works. Most of the test artifact designs have various "real” features atop a square or rectangular base. The main alternative to the square-base, multiple-feature artifacts appears to be a smaller, simpler artifact that is built at multiple positions and/or multiple orientations throughout the work volume. The proposed test parts were as large as $240 \mathrm{~mm}$ x $240 \mathrm{~mm}$ in lateral dimensions and contained features as small as $0.2 \mathrm{~mm}$ in dimension.

Table of Contents

1. Introduction

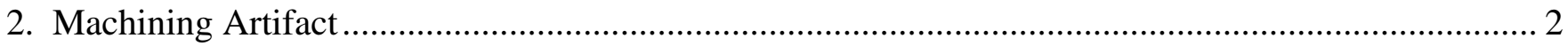

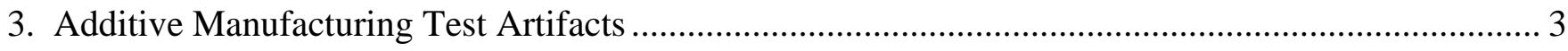

3.1 Test Artifacts for Comparing Processes for Decision Making ..................................................... 3

3.2 Test Artifacts for Evaluating Individual Processes ................................................................ 4

3.3 Test Artifacts for Evaluating Metal-based Processes.................................................................... 5

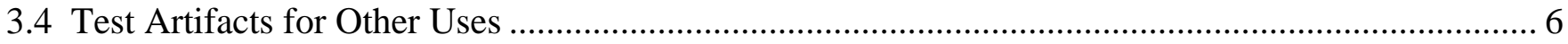

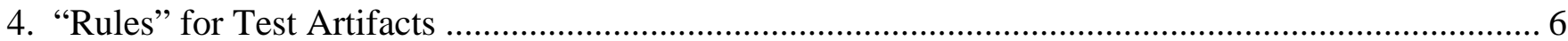

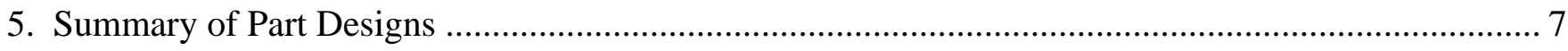

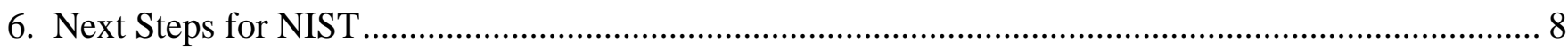

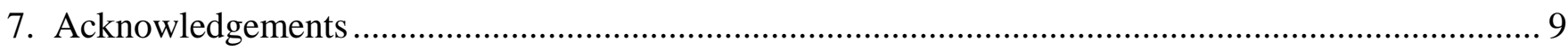

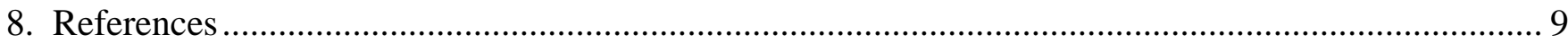




\section{Introduction}

Additive manufacturing (AM) — also known as additive fabrication, additive processes, additive techniques, additive layer manufacturing, layer manufacturing, and freeform fabrication-is defined as the process of joining materials to make objects from three-dimensional (3D) model data, usually layer upon layer, as opposed to subtractive manufacturing methodologies such as machining [1]. Additive manufacturing of functional components has grown from the initial capabilities for rapid prototyping (RP), where the resulting part, usually manufactured layer upon layer, was used for form, fit, and/or functional testing. Additive manufacturing processes demonstrate significant potential for a revolutionary, rapid art-to-part capability for making high-value, complex, and individually-customized parts. Additive processes promise the ability to manufacture parts that are difficult or impossible to make with conventional manufacturing techniques, e.g., parts with complex geometries, engineered porosity, or lattice structures. However, widespread adoption of additive processes is currently held back by deficiencies in part accuracy, surface finish, materials and material properties, process speed, and standards.

The goal of the AM projects at the National Institute of Standards and Technology (NIST) ${ }^{1}$ is to facilitate the widespread adoption of metal-based additive processes. The work focuses on metal-based processes because parts produced by these processes are likely to be used as functional components, have a higher inherent value than other materials, and require further improvements before widespread acceptance can be achieved. The projects address measurement and standards for the characterization of AM processes and equipment, as well as characterization of the materials used in and resulting from AM processes. NIST's expertise and established presence in metrology methods and standards for traditional metalcutting processes offers a unique perspective to the AM community.

In manufacturing metrology, two primary ways exist to evaluate the performance of a machine and/or a process: (1) through a series of direct measurements of machine and process characteristics, and (2) through measurements of manufactured test pieces. Manufacturing a test piece enables a composite test since most errors present in the machine and the process contribute to errors in the part. The disadvantage of composite tests is that linking specific part errors to specific machine or process error sources is often difficult. However, the advantages of test pieces are that producing parts is directly aligned with the actual purpose of the machine and specialized measuring equipment is typically not necessary since the required equipment is common for discrete part manufacturing.

A standardized test part can be used to quantitatively evaluate the performance of a machine or process. The clear benefit of a standardized part is that different machines or processes that produce the same standardized part can be easily compared. Additionally, if designed properly, the standard test part can test the limitations of the machine or process. The standardized test part can serve as a method for performance verification between users and vendors, as well as provide a platform for vendors to demonstrate improvements in their product.

This document reviews existing test artifacts used to characterize additive manufacturing processes that are reported in the literature. Several aspects of the test artifacts and their use for performance characterization are discussed, including the purposes of the studies, important features found in various test pieces, and characteristics that are desirable in test pieces. But first, an example of using a welldesigned test artifact to benefit an industry is discussed.

1 http://www.nist.gov/el/isd/sbm/matstandaddmanu.cfm; http://www.nist.gov/el/isd/sbm/fundmeasursci.cfm 


\section{Machining Artifacts}

The use of test artifacts for performance characterization is not unique to AM, and in fact, several standard artifacts are used to characterize machining processes (see, for example, Ref. [2] and Ref. [3]). One example of a test artifact that benefits U.S. manufacturers is the standard machining test artifact known colloquially as the circle-diamond-square test piece. This test piece is described in Ref. [2] and Ref. [3] (see Fig. 1), but is well established in the machining community, having been originally defined in 1969 in Ref. [4].
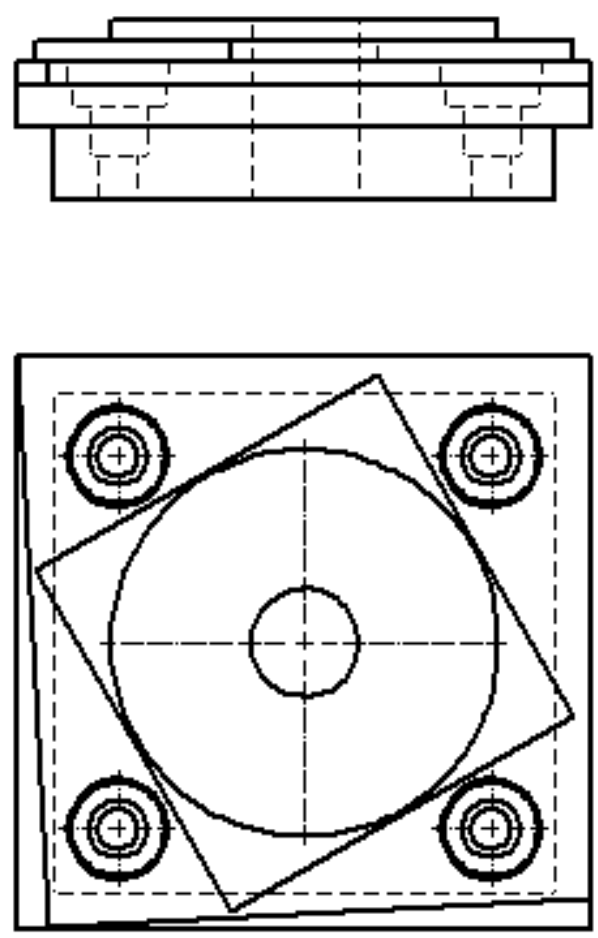

Figure 1. Test artifact, commonly known as the "circle-diamond-square," for machining centers defined in Ref. [2] and Ref. [3].

The strength of the circle-diamond-square artifact lies in its simplicity. Each feature of this artifact tests a specific aspect of the machining center used to produce it. The outside square tests the straightness of the individual axis used to cut the respective side of the square and the squareness between the two axes. The diamond feature tests the ability of the controller to execute linear interpolation of two axes. The large circle feature tests the ability of the controller to execute circular interpolation of two axes. The four pairs of concentric circles are measured for true position and characterize the machine's linear positioning accuracy. The small angle cuts test the machine's smallest actionable step. The drilled hole in the center tests the performance of the machining center's main spindle. As such, errors observed in a specific feature can often be attributed to a specific aspect of the machining center's performance. Additionally, the test part is easy to design in computer aided design (CAD) or computer aided manufacturing (CAM) software, and machining process parameters are suggested within the standard that defines the part. The test part is easy to measure, and several measurement options exist, in addition to measurement with a coordinate measuring machine (CMM).

An interesting aspect of this test part, as defined in ISO 10791-7, is that tolerances are associated with the part. These tolerances are established by the standards committee through the consensus of 
representatives from machine builders, machine users, government institutes, and academia. The tolerance values are intended to be met or exceeded by a relatively modest (not high-end) machine. It is noteworthy that the current standard tolerance levels for machining of this test part are on the order of $0.020 \mathrm{~mm}$, likely tighter than even high-end metal-based AM machine capabilities. By setting a baseline for machine performance, machine builders can often demonstrate quantitatively the extent to which their machines exceed standard specifications.

One consideration in the design of the machining test artifact is that metal cutting machines were well established when the standard test artifact was developed. Most metal cutting machines (especially three-axis machine tools) have a similar design of stacked linear stages. Since most machine configurations are similar, the observed errors and limitations are similar. As such, it is easier to design a standardized test part with features that highlight these common errors and limitations and to make it possible to compare the performance characteristics of various machines.

Additive manufacturing processes and systems are far less mature and several different machine configurations exist to correspond with different types of processes. These differences have led to a number of proposed AM test artifacts to-date, many of which have very different features and designs.

\section{Additive Manufacturing Test Artifacts}

Based on a substantial review of the available literature, the following sub-sections briefly discuss many of the different test artifacts used to characterize different aspects of the performance of additive processes. The resulting works are described in four categories: test artifacts for comparing processes for decision making, test artifacts for evaluating individual processes, test artifacts for evaluating metalbased processes, and test artifacts for other uses. This discussion is by no means exhaustive, nor is it unique.

\subsection{Test Artifacts for Comparing Processes for Decision Making}

Additive manufacturing gained prominence in the late 1980s and early 1990s as layer manufacturing or rapid prototyping (RP). Stereolithography (SLA) was the first additive RP process, followed closely by fused deposition modeling (FDM), laminated object manufacturing (LOM), and selective laser sintering (SLS). As AM matured, many more processes, such as three-dimensional printing (3DP) and polyjet, entered the market. Users wanting to benefit from the advantages of RP had to choose which of the processes best fit their application.

Many researchers proposed the use of test artifacts, often called benchmarking parts, to quantitatively compare the capabilities of the various processes [5-18]. Kruth was the first to mention a test artifact for comparing AM processes, citing a study done by two Dutch companies using a U-shaped artifact with various geometric features such as circular holes (in various orientations), circular bosses, square holes, and angled surfaces [5]. Other researchers built upon these results, adding more and/or different features, including overhangs and freeform objects, to demonstrate some of the advantages of additive processes (see Fig. 2) [7, 15]. Still more researchers followed, investigating the surface roughness of test parts in addition to geometric accuracy as a means to compare AM processes [9, 10]. As additional AM processes gained prominence, researchers added these to the comparative studies. For example, Byun added 3DP [12] and Kim added polyjet [17]. Ultimately, specific AM processes gained sufficient capability and acceptance to support multiple machine platforms and manufacturers, leading to 
comparative studies of systems within a process family, e.g., seven types of 3DP machines produced by six different manufacturers $[13,14]$.

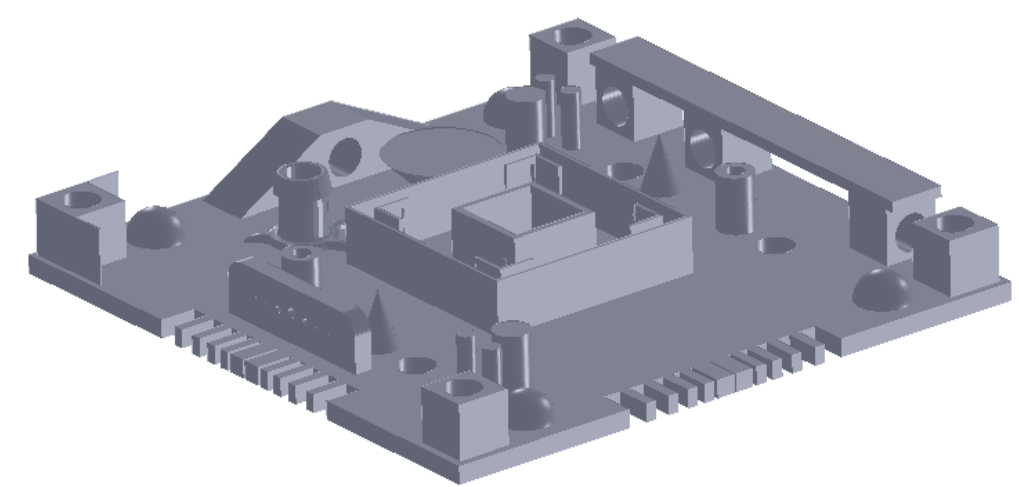

Figure 2. Solid model of the test piece used by Mahesh [15].

\subsection{Test Artifacts for Evaluating Individual Processes}

Artifacts are also used to evaluate individual processes, either when a new process or material emerges in the market [19-26] or when process improvement/optimization is the goal of the study [27, 28]. The socalled "user part" is one of the first test pieces designed to quantitatively assess the accuracy of stereolithography systems (see Fig. 3) [19]. This part was designed in 1990 by an SLA user group and focuses on assessing the machine accuracy in the $x-y$ plane. This same part or slight variations of it have been used by many other studies to characterize other additive processes, including evaluation of SLS for indirect manufacturing of metallic components (i.e., using SLS to create an intermediate, "green” part that must undergo subsequent post processing to become fully dense) [21]. Additionally, when new material options are introduced into an established process, it is important to quantify the accuracy of parts made with this new material [24, 26].

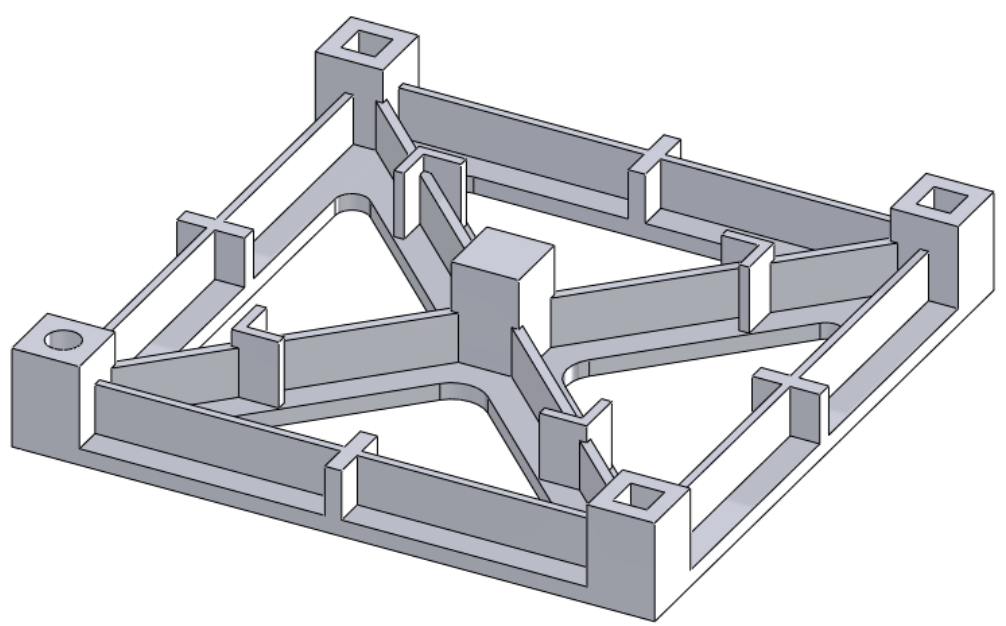

Figure 3. Solid model of the "user part.”

Development of new materials led to the first test artifacts dedicated to process improvement and optimization. During SLA's first years, newer, stronger materials were being quickly developed and introduced into user systems. The "windowpane" and "Christmas tree" test artifacts were used at this 
time to quantify the effects of changing various process settings, leading to iterative optimization of process design [27].

Examining the literature for use of test artifacts to evaluate individual processes may lead to the incorrect conclusion that using a test artifact to optimize process parameters is uncommon. In reality, most AM system manufacturers and users working on process development typically have their own internal test pieces for this purpose, though their designs remain proprietary.

\subsection{Test Artifacts for Evaluating Metal-Based Processes}

In recent years, the capabilities of metal-based AM processes have grown tremendously and these systems have emerged as viable methods for the direct manufacturing of metallic parts (i.e., using an energy source to melt and bond metal raw materials, creating a fully-dense part without the need for substantial post-processing). Numerous studies have concentrated on benchmark parts to evaluate metalbased AM processes [29-36]. The various processes that have been studied include selective laser sintering (SLS), selective laser melting (SLM), direct metal laser sintering (DMLS), electron beam melting (EBM), and micro-welding technologies. Kruth took a traditional approach by creating a test artifact with characteristic features to determine and analyze geometric errors and surface roughness (see Fig. 4). Additionally, this artifact included features to be extracted for mechanical testing to provide information about mechanical properties. The study used other features of the artifact to determine the capabilities and limitations of the different AM processes used for fabrication [29]. Castillo provided a similar comparison, though with an innovative test artifact that characterized the system's accuracy and capability to build at various angles using an “open book” feature (see Fig. 5) [30]. Ning investigated the process characteristics of DMLS using test artifacts to highlight the effects of part shrinkage during the build process, which is minimized through a shrinkage compensation function [31]. Ghany used a "realworld" test part as the reference (instead of fabricating an arbitrary design) and compared the visual appearance, mechanical properties, chemical composition, microstructure, and processing costs of the components made by different metal-based AM processes [32]. Hanumaiah manufactured numerous benchmark parts to assess geometric errors of the various features incorporated in the designs [33]. Similarly, Pessard created a test part used to evaluate the dimensional accuracy of embedded features [34]. Delgado followed with another test part used to assess geometric accuracy, but this part was fabricated many times to evaluate the accuracy and repeatability of position [35]. Finally, Cooke used a common machining test artifact to assess the geometric accuracy of its features when built using two different metal-based additive processes [36]. Differences in the process parameters, however, prevented comparative conclusions from being drawn.

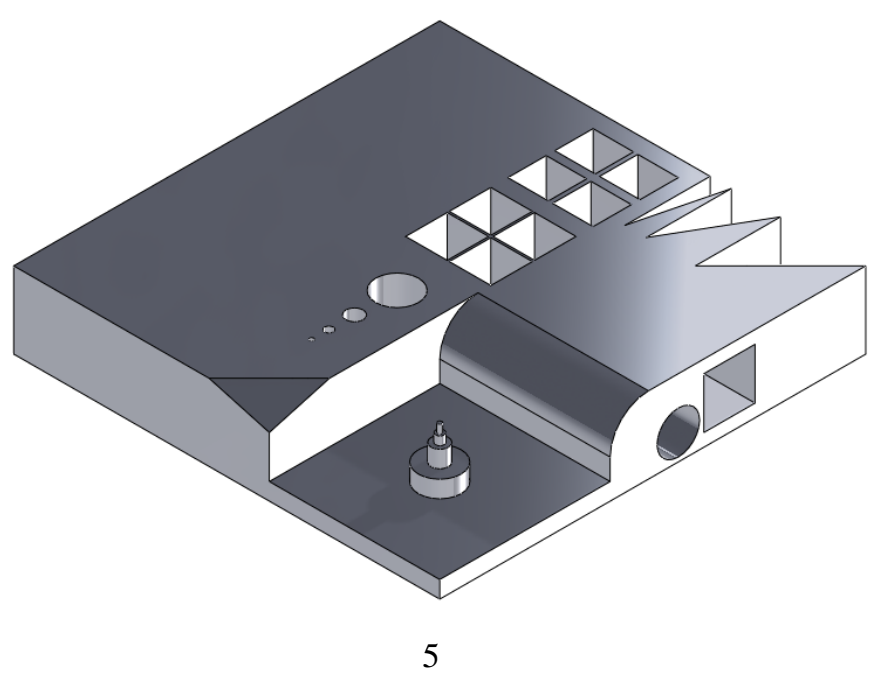


Figure 4. Approximate re-creation of the test piece used by Kruth [29].

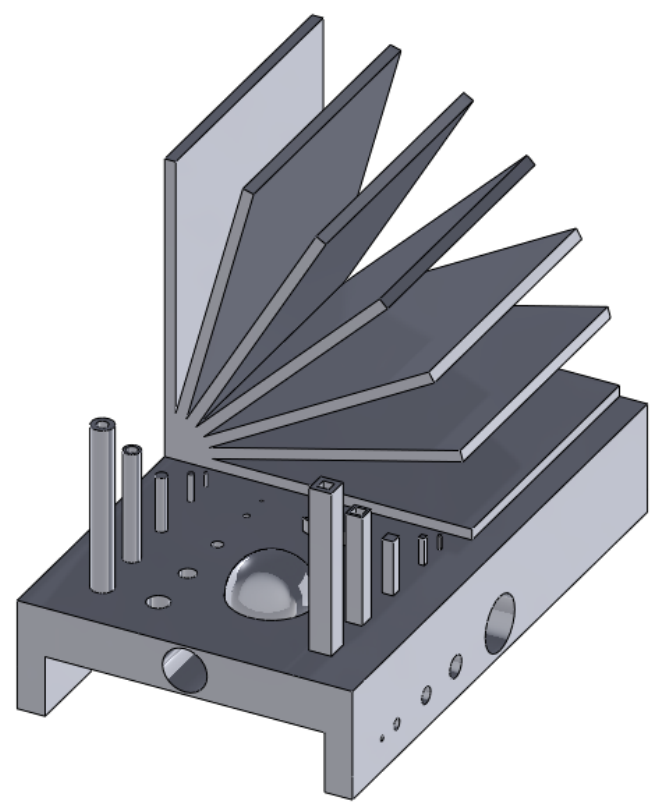

Figure 5. Approximate re-creation of the test piece used by Castillo [30].

\subsection{Test Artifacts for Other Uses}

The primary purpose of most test pieces previously mentioned was to characterize the accuracy of the machines and/or processes under test. Other researchers have used test artifacts to examine different aspects of additive processes. The layer-upon-layer nature of AM typically leads to stair-stepping on sloped and freeform structures based on the layer thickness. Accordingly, several research efforts have focused on the surface roughness of various additive processes [11, 37, 38]. Similarly, the layer-uponlayer nature of AM can lead to unique and often anisotropic mechanical properties of materials, triggering further investigations of these properties through producing test artifacts. [39, 40].

\section{4. "Rules” for Test Artifacts}

Early in the development of SLA, Richter and Jacobs saw the need for a standard accuracy test to help provide quantitative results and noted the qualities of an "ideal accuracy test part" [41]. Paraphrasing, the standard test artifact would:

- be large enough to test the performance of the machine near the extremes of the platform as well as near the center,

- $\quad$ have a substantial number of small, medium, and large features,

- have both holes and bosses to aid in verifying beam width compensation,

- not take too long to build,

- not consume a large quantity of material,

- be easy to measure, and

- have many features of a "real” part (i.e., thin walls, flat surfaces, holes, etc.). 
Other researchers [28] have followed these criteria/rules closely. Byun referenced these rules, but added that the test part should include features along all axes and should include features used to determine the minimum feature size attainable [12].

While many of these qualities are indeed important considerations in designing a test artifact, an ideal artifact would not only highlight most errors and limitations of a machine or process, but it would also correlate those errors and limitations with specific aspects of the machine or process. Kruth moved in this direction, noting that a test artifact should not only evaluate process limitations, but should also include features to allow iterative process optimization [29]. Scarvetti took this idea a step further, stating that the qualification procedure must make it possible to identify and quantify defects, but also determine the sources of the defects [42]. In order to do this, the test artifact should:

- have simple geometrical shapes, allowing perfect definition and easy control of the geometry,

- require no post-treatment or manual intervention (e.g., there should be no support structures), and

- allow measurement of repeatability [42].

In addition, several researchers state or imply the need for a test artifact to include multiples of the same feature to allow measurement of repeatability. However, including multiples of the same feature merely tests the machine or process capability to produce that same feature at different places within the work volume; it does not test the repeatability of the machine or process [43]. Various conditions may result in different systematic errors existing at different locations in the work volume, leading to differences in the shapes of the features produced in these positions. However, if multiple artifacts were produced, every feature produced in the same position in the work volume would be ideally the same.

\section{Summary of Part Designs}

While all of the AM test artifacts mentioned in this report are different, many commonalities exist. Common aspects are to be expected because much of the research builds upon the findings of previous work, and many researchers were influenced by the "rules" put forth by Richter and Jacobs [41]. Most of the test artifact designs have various "real” features atop a square or rectangular base (see Fig. 2, Fig. 3, Fig. 4, Fig. 5). The various features observed are:

- rectangular holes, bosses, and tubes (in multiple directions),

- round holes, bosses, and tubes (in multiple directions),

- spherical holes and bosses,

- conical bosses,

- L-shaped bosses,

- ramps,

- overhangs,

- angles,

- side notches,

- thin walls and fine features,

- freeform structures, and

- towers.

The sizes of the test artifacts varied, but the largest observed dimensions of the square base were $240 \mathrm{~mm}$ by $240 \mathrm{~mm}$. The smallest features observed were $0.25 \mathrm{~mm}$ thin walls (for both polymer-based and metal- 
based AM processes), $0.2 \mathrm{~mm}$ holes and bosses in polymer-based AM processes, and $0.5 \mathrm{~mm}$ holes and bosses in metal-based AM processes.

One alternative to the square-base, multiple-feature test artifact is the use of a smaller, simpler test artifact that is built at multiple positions and/or multiple orientations throughout the work volume (see Fig. 6). A second alternative approach is the use of a standard library of 3D objects or part features (e.g., spheres, cylinders, prisms, cones, etc.), rather than a single test artifact, to evaluate AM system performance. Smith proposes a library of twelve objects to benchmark AM systems, with each object designed to demonstrate and evaluate at least one important feature of the resulting parts [44]. Jurrens suggests use of a standard library of 3D features that would be built and measured in a standard way [45]. The standardized features would be built in a variety of sizes, locations, and orientations, and potentially would be supplemented with selected "real-world" parts.

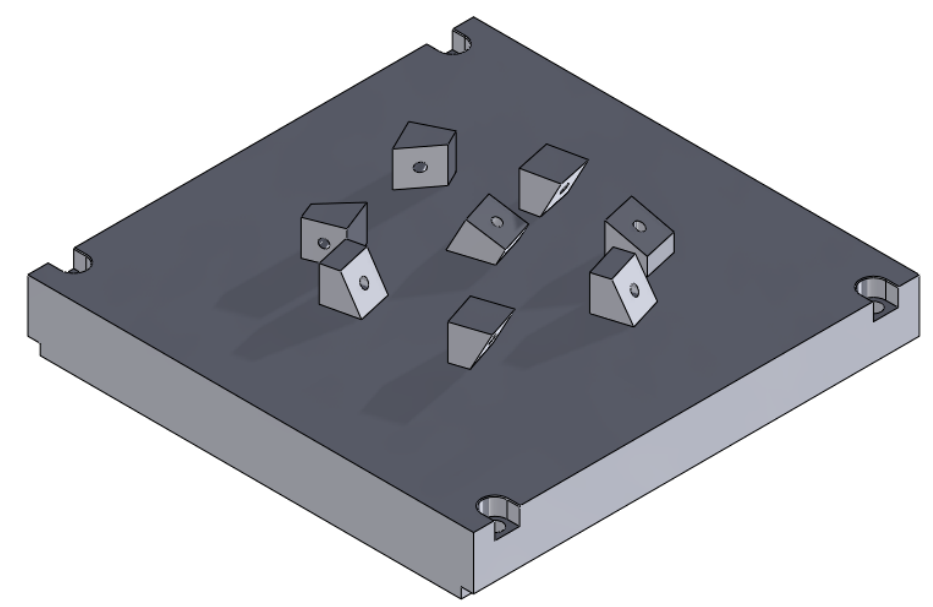

Figure 6. Approximate re-creation of Delgado’s simple artifact in various orientations on an AM build platform [35].

\section{Next Steps}

This review was a first step toward the development of an industry-accepted, standardized test artifact for AM. With knowledge of the work already documented in the literature, the next step is to determine the characteristics of a "good" test part. A candidate standard test artifact will be designed that incorporates as many of the characteristics of a good test part as possible, and then tested by building the candidate artifact on the existing DMLS machine at NIST. Lessons learned while building the first test pieces will certainly lead to improvements over the original proposed design. Concurrent to these efforts, the feasibility for using one standardized test artifact for all types of additive processes will be assessed. Proper performance characterization may require different test piece designs. The final design of the candidate test artifact(s) evaluated using the DMLS system, along with an assessment of other AM processes for which the test artifact(s) are also relevant, will be the focus of a future NIST report. 


\section{Acknowledgements}

The authors would like to thank Regina Avila of the NIST Information Services Office for her assistance in compiling the articles referenced in this report.

\section{References}

[1] ASTM, F2792 - 10e1 Standard Terminology for Additive Manufacturing Technologies. (2010).

[2] ASME, B5.54: Methods for Performance Evaluation of Computer Numerically Controlled Machining Centers.

[3] ISO, 10791-7: Test conditions for machining centers--Part 7: Accuracy of a finished test piece.

[4] NAS, 979 Uniform Cutting Tests--NAS series metal cutting equipment specifications. (1969).

[5] J. P. Kruth, Material Incress Manufacturing by Rapid Prototyping Techniques, CIRP Annals Manufacturing Technology. 40 (2), 603-614 (1991).

[6] G. Lart, Comparison of Rapid Prototyping Systems, Proceedings of the 1st European Conference on Rapid Prototyping, University of Nottingham, U.K., 243-254.

[7] T. H. C. Childs and N. P. Juster, Linear and Geometric Accuracies from Layer Manufacturing, CIRP Annals - Manufacturing Technology. 43 (1), 163-166 (1994).

[8] D. Jayaram, A. Bagchi, C. C. Jara-Almonte and S. O'Reilly, Benchmarking of Rapid Prototyping Systems - Beginning to Set Standards, Proceedings of the Solid Freeform Fabrication Symposium. 146153 (1994).

[9] R. Ippolito, L. Iuliano and A. Gatto, Benchmarking of Rapid Prototyping Techniques in Terms of Dimensional Accuracy and Surface Finish, CIRP Annals - Manufacturing Technology. 44 (1), 157-160 (1995).

[10] F. Xu, Y. S. Wong and H. T. Loh, Toward generic models for comparative evaluation and process selection in rapid prototyping and manufacturing, Journal of Manufacturing Systems. 19 (5), 283-296 (2000).

[11] R. I. Campbell, M. Martorelli and H. S. Lee, Surface roughness visualization for rapid prototyping models, Computer-Aided Design. 34 717-725 (2002).

[12] H.-S. Byun and K. Lee, Design of a New Test Part for Benchmarking the Accuracy and Surface Finish of Rapid Prototyping Processes

Computational Science and Its Applications - ICCSA 2003, in: V. Kumar, M. Gavrilova, C. Tan and P. L’Ecuyer, Springer Berlin / Heidelberg, (2003) 989-989.

[13] T. Grimm, Rapid Prototyping Benchmark: 3D Printers, (2003).

[14] T. Grimm, 3D Printer Benchmark: North American Edition, (2010).

[15] M. Mahesh, Y. Wong, J. Y. H. Fuh and H. T. Loh, Benchmarking for comparative evaluation of RP systems and processes, Rapid Prototyping J. 10 (2), 123-135 (2004).

[16] M. Mahesh, Y. S. Wong, J. Y. H. Fuh and H. T. Loh, A six-sigma approach for benchmarking of RP\&M processes, International Journal of Advanced Manufacturing Technology. 31 (3-4), 374-387 (2006).

[17] G. D. Kim and Y. T. Oh, A benchmark study on rapid prototyping processes and machines: Quantitative comparisons of mechanical properties, accuracy, roughness, speed, and material cost Proceedings of the Institution of Mechanical Engineers, Part B: Journal of Engineering Manufacture. 222 (2), 201-215 (2008).

[18] T. Brajlih, B. Valentan, J. Balic and I. Drstvensek, Speed and accuracy evaluation of additive manufacturing machines, Rapid Prototyping J. 17 (1), 64-75 (2011).

[19] E. P. Gargiulo, Stereolithography process accuracy: user experience, Proceedings of the 1st European Conference on Rapid Prototyping, University of Nottingham. 187-207 (1992). 
[20] B. Bedal and H. Nguyen, Advances in Part Accuracy, in: Stereolithography and Other RP\&M Processes, P. F. Jacobs, American Society of Mechanical Engineers, (1996) 149-182.

[21] M. Geiger, A. Coremans, N. Neubauer and F. Niebling, Advanced rapid prototyping by laser beam sintering of metal prototypes: design and development of an optimized laser beam delivery system Proc. SPIE 2787. 103-114 (1996).

[22] D. Dimitrov, W. van Wijck, K. Schrevel, N. de Beer and J. Meijer, An investigation of the capability profile of the three dimensional printing process with an emphasis on the achievable accuracy, CIRP Annals. 52 (1), 189-192 (2003).

[23] D. Dimitrov, W. van Wijck, K. Schreve and N. de Beer, Investigating the achievable accuracy of three dimensional printing, Rapid Prototyping J. 12 (1), 42-52 (2006).

[24] N. Hopkinson and T. B. Sercombe, Process repeatability and sources of error in indirect SLS of aluminium, Rapid Prototyping J. 14 (2), 108-113 (2008).

[25] W. M. Johnson, M. Rowell, B. Deason and M. Eubanks, Benchmarking Evaluation of an Open Source Fused Deposition Modeling Additive Manufacturing System, (2011).

[26] K. Senthilkumaran, P. M. Pandey and P. Rao, Statistical modeling and minimization of form error in SLS prototyping, Rapid Prototyping J. 18 (1), (2011).

[27] H. Nguyen, J. Richter and P. Jacobs, On Windowpanes and Christmas-Trees: Diagnostic Techniques for Improved Part Accuracy, Third Int. Conf. Rapid Prototyping. 41-62 (1992).

[28] S. L. Campanelli, G. Cardano, R. Giannoccaro, A. D. Ludovico and E. L. J. Bohez, Statistical analysis of the stereolithographic process to improve the accuracy, Computer-Aided Design. 39 (1), 8086 (2007).

[29] J.-P. V. Kruth, B.; Van Vaerenbergh, J.; Mercelis, P. , Benchmarking of different SLS/SLM processes as rapid manufacturing techniques, Int. Conf. Polymers \& Moulds Innovations (PMI), Gent, Belgium, April 20-23, 2005. (2005).

[30] L. Castillo, Study about the rapid manufacturing of complex parts of stainless steel and titanium, (2005).

[31] Y. Ning, Y. S. Wong, J. Y. H. Fuh and H. T. Loh, An approach to minimize build errors in direct metal laser sintering, Ieee Transactions on Automation Science and Engineering. 3 (1), 73-80 (2006).

[32] K. A. Ghany and S. F. Moustafa, Comparison between the products of four RPM systems for metals, Rapid Prototyping J. 12 (2), 86-94 (2006).

[33] N. Hanumaiah and B. Ravi, Rapid tooling form accuracy estimation using region elimination adaptive search based sampling technique, Rapid Prototyping J. 13 (3), 182-190 (2007).

[34] E. Pessard, P. Mognol, J. Y. Hascoet and C. Gerometta, Complex cast parts with rapid tooling: rapid manufacturing point of view, International Journal of Advanced Manufacturing Technology. 39 (9-10), 898-904 (2008).

[35] J. Delgado, J. Ciurana, C. Reguant and B. Cavallini, Studying the repeatability in DMLS technology using a complete geometry test part. (2010).

[36] A. L. Cooke and J. A. Soons, Variability in the Geometric Accuracy of Additively Manufactured Test Parts, 21st Annual International Solid Freeform Fabrication Symposium, Austin, Texas, USA, 1-12.

[37] P. M. Pandey, N. V. Reddy and S. G. Dhande, Improvement of surface finish by staircase machining in fused deposition modeling, Journal of Materials Processing Technology. 132 (1-3), 323-331 (2003).

[38] A. Armillotta, Assessment of surface quality on textured FDM prototypes, Rapid Prototyping J. 12 (1), 35-41 (2006).

[39] O. S. Es-Said, J. Foyos, R. Noorani, M. Mendelson, R. Marloth and B. A. Pregger, Effect of layer orientation on mechanical properties of rapid prototyped samples, Mater. Manuf. Process. 15 (1), 107122 (2000).

[40] V. Vega, J. Clements, T. Lam, A. Abad, B. Fritz, N. Ula and O. S. Es-Said, The Effect of Layer Orientation on the Mechanical Properties and Microstructure of a Polymer, Journal of Materials Engineering and Performance. 20 (6), 978-988 (2011). 
[41] J. Richter and P. Jacobs, Accuracy, in: Rapid Prototyping \& Manufacturing, P. Jacobs, Society of Manufacturing Engineers, (1992) 287-315.

[42] D. Scaravetti, P. Dubois and R. Duchamp, Qualification of rapid prototyping tools: proposition of a procedure and a test part, The International Journal of Advanced Manufacturing Technology. 38 (7), 683690 (2008).

[43] M. Shellabear, Model manufacturing processes--State of the art in rapid prototyping, RAPTEC Task 4.2, Report 1. (1998).

[44] R. Smith, Standard Test-Files for Benchmarking RP Systems, Third International Conference on Rapid Prototyping. (1992).

[45] K. K. Jurrens, Standards for the Rapid Prototyping Industry, Rapid Prototyping J. 5 (4), 169-178 (1999). 